\title{
MEMBERS OF THE COUNCIL
}

\section{9}

\section{OFFICERS}

Frank Morley, President.

$\left.\begin{array}{l}\text { G. D. BIRKHOFF, } \\ \text { FloRIAN CAJORI, }\end{array}\right\}$ Vice-Presidents.

F. N. Cole, Secretary.

J. H. TANNER, Treasurer.

D. E. SMith, Librarian.

F. N. Colf,

VIRGIL SNYDER, Committee of Publication.

J. W. Youna,

\section{EX-PRESIDENTS}

R. S. WOODWARD,

E. H. MOORE,

T. S. FISKE,
W. F. OSGOOD,

H. S. WHITE,

H. B. FinE,
E. B. VAN Vleck,

E. W. Brown,

L. E. Dickson.

\section{Elected Members \\ To serve until December, 1919}

G. C. Evans,

G. H. LING,

L. A. Howland,

R. L. MOORE.

To serve until December, 1920

R. C. ARchibald,

DunhaM JaCKson,
D. N. LEHMER,

J. B. SHAW.

To serve until December, 1921

H. E. HAWKES,

W. A. HURWITZ,
A. C. LUNN,

C. N. MOORE.

Editorial Committee of the Transactions

D. $R$ Curtiss,

L. P. Eisenhart,

P. F, SмIтH.

Secretary of the Chicago Section

E. J. Moulton. 